\title{
Manuel Bandeira e Carlos Drummond de Andrade: poetas de almanaque?
}

\author{
Manuel Bandeira and Carlos Drummond de \\ Andrade: almanac poets?
}

Maria Aparecida Ribeiro

Universidade de Coimbra/CLP/CLEPUL

\section{DoI}

https://doi.org/10.37508/rcl.2021.n46a467

\section{RESUMO}

Com intenções diferentes das do Almanaque de Lembranças Luso-Brasileiro e do Novo Almanaque de Lembranças Luso-Brasileiro organizados ambos por familiares de Antônio Feliciano de Castillho, Alberto de Serpa coligiu em dois almanaques, com nomes idênticos aos acima citados, poesias de autores brasileiros e portugueses. Entre eles, Manuel Bandeira e Carlos Drummond de Andrade. Pretende-se, neste artigo, procurar os caminhos que levaram Serpa a tal inclusão.

Palavras-chave: Alberto de Serpa; Almanaque de Lembranças Luso-Brasileiro; Novo Almanaque de Lembranças Luso-Brasileiro; Manuel Bandeira; Carlos Drummond de Andrade

\section{Abstract}

With different intentions from those of the Luso-Brazilian Souvenirs Almanac (Almanaque de Lembranças Luso-Brasileiro) and of the New Luso-Brazilian Souvenirs Almanac (Novo Almanaque de Lembranças 
Luso-Brasileiro), both organized by the relatives of Antônio Feliciano de Castillho, Alberto de Serpa collected in other two almanacs, with identical names to those mentioned above, poetry by Brazilian and Portuguese authors. Among them, Manuel Bandeira and Carlos Drummond de Andrade. It is intended, in this essay, to seek the paths that led Serpa to such inclusion.

KEYWORDS: Alberto de Serpa; Almanaque de Lembranças Luso-Brasileiro; Novo Almanaque de Lembranças Luso-Brasileiro; Manuel Bandeira; Carlos Drummond de Andrade

Para Beatriz Weigert, que, como já diz o nome, leva aos outros a felicidade

\section{Almanaques, almanaques, almanaques...}

No mundo lusófono, muitas pessoas enviavam poesias de sua lavra para os almanaques, tentando conseguir divulgação de seus versos, na esperança de se tornarem conhecidas. Entre os almanaques mais famosos, que serviram a Portugal e suas colônias, assim como ao Brasil, figura o Almanaque de Lembranças, depois Almanaque de Lembranças Luso-Brasileiro, e, finalmente, Novo Almanaque de Lembranças Luso-Brasileiro, que circulou entre 1851 e 1932, dirigido sucessivamente por Alexandre Magno de Castilho (irmão de Antônio Feliciano), Alexandre Magno de Castilho (sobrinho de ambos), Antônio Xavier Rodrigues Cordeiro e Armando de Lima Pereira. Os colaboradores dessas publicações às vezes utilizavam pseudônimos; às vezes assinavam seus próprios nomes. As contribuições em verso variavam de qualidade, a ponto de se haver cunhado a expressão “poeta de almanaque”. Uma observação do editor dá conta da má qualidade dos poetas: "Por Cristo e por quantos santos há no corte do céu, não me matem com versos! Nisso já pouco se admite hoje, e a maior parte das poesias que se me remetem está cem graus abaixo do mau" (Almanaque de Lembranças Luso-Brasileiro para 1860 (bissexto), p. 5). 
Já na segunda metade do século XX, surgem, em 1954, o Almanaque de Lembranças Luso-Brasileiro e o Novo Almanaque de Lembranças Luso-Brasileiro. Se, no primeiro, encontramos poemas de Serpa dedicados a Manuel Bandeira, Drummond, Ribeiro Couto, Cecília Meireles, Augusto Frederico Schmidt, Marques Rebelo, José Lins do Rego, Álvaro Lins, bem como um dedicado à morte de Mário de Andrade, que falecera naquele ano, no segundo, o Novo Almanaque, encontramos respostas de alguns desses poetas, nomeadamente Bandeira e Drummond.

Os almanaques ligando Portugal e Brasil tiveram origem na ideia de Castilho, e objetivo bem diverso: além de aceitarem colaboração de quem quer que fosse, deveriam ser

um nexo mais entre nós "portugueses" e os nossos irmãos brasileiros, (que) estreite e fortifique os vínculos de sangue que mutuamente nos prendem e já que é livro de lembranças leve também lembranças da pátria, aos que longe dela levem saudades!.... (Almanaque de Lembranças Luso-Brasileiro para 1856, p. 27).

Além do que diziam seus organizadores, tinham esses almanaques, como tão bem demonstra Eliana de Freitas Dutra, um discurso colonial/pós-colonial, que instrumentalizaria o desejo português de manter sua influência cultural sobre a jovem nação brasileira, através da construção da noção imaginária de uma comunidade fraternal entre os dois países e da sustentação do ideal de uma harmonia cultural entre Brasil e Portugal. (DUTRA, 2005, p. 117).

Já o Almanaque de Serpa era dedicado "a Nuno Simões, para quem os brasileiros e portugueses são a mesma gente" (SERPA, 1954a, p. 3)

Por outro lado, enquanto os almanaques dos Castilhos eram vendidos, o volume organizado por Alberto de Serpa, como se afirma na folha de rosto do Novo Almanaque "não entra no Mercado comercial 
e é destinado a ofertas aos colaboradores", cujos poemas estampava (SERPA, 1954b: folha de rosto).

E o que era esse Novo Almanaque de Lembranças Luso-Brasileiro? Definido como "uma simples flor, mas viva, de Amizade", "na terra áspera que por aí se pisa" (SERPA, 1954b: 5), a publicação juntava os versos de agradecimento dos autores incluídos no Almanaque elaborado em 1952 e publicado, como se disse acima, em 1954. Eram esses poetas os portugueses Campos de Figueiredo, José Régio, Francisco Costa, Pedro Homem de Mello; e os brasileiros Manuel Bandeira, Carlos Drummond de Andrade, Ribeiro Couto. Aos agradecimentos, nesse Novo Almanaque, Alberto juntou três poemas de sua lavra: "O poeta e os ventos", "Aos confrades brasileiros”; “Aos confrades portugueses".

Mas como teriam Bandeira e Drummond, por exemplo, ido parar no Novo Almanaque de Serpa?

\section{O caso de Bandeira}

Talvez Alberto de Serpa tenha sido o primeiro poeta português a estabelecer com Bandeira uma interlocução, no sentido que lhe empresta Antoine Compagnon, em seu Trabalho da Citação. Se, num dos primeiros livros de poesia publicados (e rejeitados) por Serpa - Evohe (1924) - é possível que se queira ver um eco do grito de Bandeira em "Bacanal", poema constante de Carnaval (1919), nos versos de "Poesia", que Alberto dedica a Fernando Pessoa, incluídos em Descrição (1935), reflete-se a "Poética” bandeiriana, publicada em Libertinagem. Preocupado em contrariar a regra, o comedimento, a imitação, a palavra precisa, culta, vernácula, a rima, a correção sintática, o respeito à métrica tradicional, o recifense quer o lirismo que é libertação, o lirismo dos bêbedos, o lirismo dos palhaços, onde todas as palavras e ideias possam entrar. Alberto também clamava pela independência do poeta: 
(...) O poeta é independente. Só ele sabe.

Sobre as suas ideias, sobre os seus sentimentos, não podem pesar leis com séculos de existência.

$\mathrm{Na}$ força com que exprime uma ideia violenta, na brandura que um sentimento muito calmo arrasta, na pressa duma corrida, no vagar duma música dolente, no que tem de exprimir, está o ritmo do poeta.

Não lhe venham dizer que um verso está errado e sem rima, se a alma está para lá de todas as convenções.

Há sentimentos que cabem numa letra, e um verso pode não caber em todos os livros do mundo (SERPA, 1935, p. 6o-61).

Mas há mais: neste mesmo livro, Serpa dedica o poema "Manhã" a Bandeira (SERPA, 1935, p. 13-14). E, em 1944, incluiria no seu As Melhores Poesias Brasileiras, textos do pernambucano: "Boda espiritual”, “Os Sapos”, “Evocação do Recife”, "Vou-me embora pra Pasárgada”, "Canção do vento e da minha vida”.

As cartas de Bandeira a Alberto de Serpa, existentes na Biblioteca Pública Municipal do Porto, que comprou em leilão toda a correspondência recebida e colecionada pelo poeta português, revelam muito das afinidades e da amizade entre os dois homens de Letras. O Arquivo-Museu de Literatura Brasileira da Fundação Casa de Rui Barbosa, infelizmente, possui pouquíssimas cartas de Serpa para Bandeira. É que a correspondência recebida pelo pernambucano, ficou, depois de sua morte, sem ser organizada ou mesmo devidamente guardada, na casa de Maria de Lourdes Heitor de Sousa, com quem ele viveu em seus últimos tempos. E isso durante 10 anos, pois a doação à Fundação Casa de Rui Barbosa se deu em 3 de janeiro de 
1978 (Fundação Casa de Rui Barbosa, 1989, p. 11). Além disso, pode ter acontecido que parte dessa correspondência estivesse dentro de livros, que ficaram no apartamento da Av. Beira-Mar e que foram deixados em testamento, pelo próprio Bandeira, à Academia Brasileira de Letras. Do Inventário do Arquivo Manuel Bandeira, publicado pela própria Fundação Casa de Rui Barbosa, em 1989, constam apenas três cartas, escritas por Alberto de Serpa, entre 7 de setembro de 1947 e 28 de junho de 1948.

Escrevendo de "Leça, a de António Nobre", com data de 7 de setembro de 1947, Alberto de Serpa pede a Bandeira livros para a Biblioteca Gonçalves Dias por ele criada e envia, "como bandeira de paz", "uma folhinha de provas da $1^{\mathrm{a}}$ edição do Só - a portuguesa: 'a de Paris', emendada pelo punho do nosso Poeta" (cf. AMLB/MB ${ }^{1} 117$ ср). Na carta datada de Leça, 21 de dezembro de 1947, o portuense pede a Bandeira versos para serem publicados como abertura do segundo número de Brasil Cultural, que "o Renato de Mendonça ajuda a fazer" e onde vai sair uma "noticiazinha minha sobre a Antologia dos Poetas Bissextos". Também pede livros para Salgado Júnior. E perguntando quando irá Bandeira a Portugal, informa da impossibilidade de irem os poetas portugueses ao Brasil (cf. AMLB/MB 117cp). Na de 28 de junho de 1948, também escrita em Leça, pede um favor para Antônio Jacinto Júnior (cf. AMLB/MB 117 cp).

Se essas poucas cartas de Serpa já nos dizem alguma coisa, vejamos o que revelam as de Bandeira.

Em 18 de janeiro de 1935, ao agradecer a Alberto o livro Varanda, cujo trecho de inspiração bandeiriana foi acima transcrito, Manuel diz que lhe agradou em especial o poema "Abandono", porque encontra nos seus versos "aquela constante lírica portuguesa que re-

1 A correspondência de Manuel Bandeira existente no Arquivo-Museu da Fundação Casa de Rui Barbosa será, daqui em diante, indicada como AMLB/MB. 
monta aos cancioneiros" (BPMP: SER-M-99-1)². Noutra carta, de 4 de fevereiro de 1938 (BPMP: SER-M-99-2), o pernambucano diz ter "grande vontade de conhecer de-vagar Portugal" e envia cópia de um seu retrato feito por Portinari, explicando ironicamente que o pintor “coloca em primeiro lugar as suas exigências plásticas, o que o levou a me dar - a mim, poeta de pescoço fraco - um cachaço de campeão de peso pesado”.

Nessa mesma carta, também pede um retrato de Alberto de Serpa. Esse pedido de troca de retratos tem por base, para Bandeira, como afirma em carta de 5 de agosto de 1938 , em que solicita ao poeta portuense o retrato de José Régio, por quem diz várias vezes ter admiração, a necessidade de "situar" essa "admiração numa fisionomia" (BPMP-M-SER-99-5).

Numa outra carta, datada de 22 de fevereiro de 1938, Manuel diz a Alberto:

Todo poeta tem o seu pé-de-meia de poemas inéditos. Eu não. A poesia é uma coisa que acontece de raro em raro. Quando tenho alguns versos novos, vendo-os logo, ou dou-os a amigos daqui, heróis que como vocês aí sustentam desinteressadamente revistas de vanguarda.

Presentemente, os únicos versos inéditos que tenho para lhes oferecer são estas duas bagatelas ${ }^{3}$ que envio. Não as julgo à altura da bela "Revista de Portugal”. Você e Nemésio decidam se lhes convém publicá-las. (BPMP: SER 99-3).

2 A correspondência de Manuel Bandeira existente na Biblioteca Pública Municipal do Porto será, daqui em diante, indicada como BPMP-M-SER. Da mesma forma será indicada a correspondência de Carlos Drummond de Andrade com Serpa.

3 Possivelmente as "duas bagatelas" foram "Desafio" e "Canção", publicados, respectivamente, nos $\mathrm{n}^{\text {os }} 3$ e 4 da Revista de Portugal, respectivamente de abril e de julho de 1938 . 
Mas Bandeira deve ter enviado também o poema “Desafio”, depois incorporado em Lira dos Cinquent'Anos (1940), pois em carta de 13 de maio de 1938, em que acusa a recepção de outra de Alberto de Serpa datada de 27 de abril, diz que enviou os poemas pedidos e considera: "se vocês acharem irreverência excessiva falar-se de bunda em público, podem substituir essa coisa tão bonita por vulto, por exemplo; ficando, pois, os versos, assim: 'ver assentado na popa /o vulto do meu amor"'. E acrescenta que Afonso Arinos de Melo Franco lhe disse ser a palavra pouco conhecida em Portugal, mas que "Aqui a palavra é vulgar, demasiado vulgar! No entanto, em família, é muito empregada" (BPMP-M-SER-99(4)).

Nessa mesma carta, mostra ter sabido por Alberto de Serpa do alargamento da Presença a outros autores de outros territórios da língua portuguesa, o que acha ótima ideia, e considera:

A melhor gente aqui adota o ponto de vista tão magistralmente exposto pelo Gilberto Freyre na conferência que fez aí: formamos brasileiros, portugueses e colônias portuguesas um só bloco de cultura, e teremos grande vantagem em nos aproximarmos. $\mathrm{O}$ que tem estragado muito nas aproximações são os profissionais do intercâmbio. (BPMP-M-SER-99(4)).

Pelas palavras de Bandeira ainda nessa carta, fica-se a saber que Serpa está a preparar um Almanaque de Lembranças. E mais: que o poeta pernambucano foi nomeado interinamente professor catedrático de Literatura Geral do Colégio Pedro II, onde "no $2^{\circ}$ ano do Curso Complementar Juridico dá-se com certo desenvolvimento a literatura portuguesa". Por isso, diz andar “precisando de algum livro ou ensaio onde se fale da literatura atual (a partir de Eça na prosa e Nobre no verso), mas com largueza que abranja os esquivos, pouco conhecidos", acrescentando:

Do Portugal de agora conheço alguma coisa do grupo "Presença"; assim mesmo o que sei necessita uma sistematização. O que li no 
Manuel Anselmo não me satisfaz, embora já seja de alguma utilidade. (BPMP-SER-M-99(4)).

Encantado com o Auto da Alma, que leu com outras obras de Gil Vicente, em que esteve "mergulhado" durante o verão em Petrópolis, Bandeira, escrevendo ainda da serra, no dia 6 de fevereiro de 1939, informa Serpa que já comprou o Cancioneiro da Ajuda e que recebeu apenas o volume das cantigas de amigo por ele enviado, mas que faz questão de ter a obra completa. Aproveita também para cobrar de Alberto Considerações Pessoais (de Adolfo Casais Monteiro) e $O$ Mistério da Poesia (de João Gaspar Simões), além de A Vida é o Dia de Hoje, do próprio Serpa, cujo título considera “apetitosíssimo”. E perguntando quando sairá a nova Presença, informa "Vou mandar-lhe para ela um "Soneto Inglês" que fiz ultimamente. Será para quando voltar ao Rio (fins deste mês)” (BPMP-M- SER-99(8)).

A 13 de dezembro de 1940, Bandeira acusa o recebimento de Lisboa é Longe, que tem "lido e relido encantado com aquele lirismo tão simples e que parece sair do âmago das coisas simples”, e diz ter observado, por carta de Serpa de 18 de novembro, que o amigo não recebeu "dois grandes pacotes", contendo exemplares de seu último livro, onde reuniu todas as suas produções poéticas desde $A$ Cinza das Horas até os inéditos e que chamou Lira dos Cinquent'Anos, "parodiando o Álvares de Azevedo". Os exemplares, com dedicatória, destinavam-se "a vários amigos daí: o Adolfo Casais Monteiro, o Antonio Botto, o Queirós, etc!" (BPMP-M-SER-99(11)).

A insistência em receber um retrato de José Régio reaparece em carta de Bandeira a Serpa, datada de 23 de abril de 1941:

O Régio me mandou livros duas ou três vezes ('Jogo da Cabra Cega', 'As Correntes e as Individualidades da moderna poesia portuguesa' e 'Encruzilhadas de Deus'), mas nunca me benze com uma carta ou retrato dele. 
E chega mesmo a concluir dizendo: "Veja se me furta um retrato do homem” (BPMP-M-SER-99 (12)(o1 e 02)).

A mesma reclamação aparece na carta de 30 de dezembro de 1941. Nela, depois de acusar recebimento de carta de Serpa datada de 2 de setembro de 1941 ("A sua carta de 2 de setembro me deu o prazer que sempre tenho ao saber notícias suas e dos bons amigos de Portugal."), Bandeira lembra a guerra, deseja um bom 1942, fala sobre Ribeiro Couto, dá notícias sobre a situação do Brasil, comenta sua forma de fazer poesia e, mais uma vez, diz da necessidade que tem de um retrato do autor de Poemas de Deus e do Diabo:

Nesta época terrível, neste sangrento Natal, o pensamento da gente está continuamente girando de um lado para outro - pois em toda a parte há amigos. De vez em quando Portugal preocupa nesta vigília de sobressaltos. Deus permita que vocês possam atravessar incólumes estes tempos medonhos.

A você a aos seus envio os melhores votos para o Ano Novo.

Por aqui vamos indo. Fizemos uma declaração de solidariedade à América do Norte e provavelmente teremos, com o tempo, de a demonstrar praticamente.

O nosso Ribeiro Couto foi pilhado pela guerra nos Estados Unidos. Tinha partido há cerca de dois meses para Havana, como delegado a um Congresso de Cooperação Intelectual, mas não sei se vai regressar já.

Dê no Régio um grande abraço de Natal. Diga-lhe que não cessarei de reclamar um instantâneo dele: sinto a necessidade de situar a minha admiração e afeto.

Estou presentemente trabalhando na minha antologia dos nossos simbolistas. Versos meus novos não há. Ando cheio de trabalhos. Ora, a poesia em mim só pode nascer de uma profunda ociosidade - qualquer agitação material nas águas da consciência perturba a cristalização... Não faz mal, porque o melhor de mim creio que já dei. (BPMP: M-SER-99 (13)-o1 e M-SER-99 (14)). 
Sempre noticiando os trabalhos que tem em mãos, enviando ou acusando o recebimento de livros, Bandeira volta a escrever a Alberto em 9 de maio de 45: diz que apreciou "muitíssimo" a "carta crítica sobre a Antologia dos Bissextos"; que envia um exemplar da Revista de Língua Portuguesa; pergunta se Alberto recebeu as suas "Poesias Completas" e diz estar terminando um volume de "umas duzentas páginas”, sobre a vida de Gonçalves Dias, "biografia quase linear sem nenhum aparato erudito" (BPMP-M-SER-99(14)). Também contando sobre o que escreve, agradecendo o recebido e informando das providências tomadas para corresponder aos pedidos de livros que recebeu de Serpa, Bandeira, na carta de 14 de dezembro de 1947, diz de sua alegria por ter recebido as provas da primeira edição de Só, com as emendas feitas pela mão de Antônio Nobre, o que o deixou "muito comovido"; informa ter encomendado a um alfarrabista as obras solicitadas por Salgado Júnior e que este já lhe conseguiu a Cena Policiana, publicada por João Ribeiro na extinta Revista de Língua Portuguesa. Também diz que vai enviar livros seus para a Biblioteca fundada por Serpa e pede um livro de José Régio ("Não é Biografia o título?") (BPMP-M-SER-99(15)).

A carta a Serpa datada de agosto de 1949, apesar do intervalo temporal que mantém com esta última, centra-se mais uma vez no pedir e enviar livros, e nas informações sobre os trabalhos em curso. Bandeira diz que conseguiu o Auto de Rodrigo e Mendo para Salgado Júnior, e solicita que este lhe envie o seu "trabalho sobre Menina e Moça”. E informando que organizou umas apostilas sobre literatura hispano-americana, para o novo curso que rege na Faculdade, comenta: "Há muito tempo (mais de um ano!) não escrevo uma linha de poesia. Se já não me tivesse acontecido tal, ficaria pensando ter entrado em definitiva menopausa lírica" (BPMP- M- SER- 99(16)).

E é assim, numa amizade tecida em cartas, mediada pelo gosto comum por Antônio Nobre e pelo interesse de Alberto de Serpa pela poesia brasileira e o de Bandeira pela portuguesa, pelo desejo de am- 
bos de se conhecerem pessoalmente, que o pernambucano entra no Almanaque de Lembranças Luso-Brasileiro, organizado pelo poeta português desde 1952, mas publicado em 54. Bandeira se manifesta dessa forma, em carta de 13 de junho de 1954:

Acabo e ler o Almanaque de Lembranças Luso-Brasileiro. O título levou-me para os meus tempos de menino no bairro de Laranjeiras, quando eu me iniciava nas charadas "novíssimas", nos logogrifos e nos "enigmas pitorescos" do famoso almanaque, onde também me despertavam a curiosidade os versinhos de segunda ou terceira ordem de colaboradores do vasto império português (José Bastos Nogueira, Angola; Cecília da Cunha, Goa; Manuel da Costa, Macau; João Pedrosa, Funchal; etc) e me vinha vontade de fazer o que fez o ano passado o Gilberto Freyre! Viajar por terras portuguesas de África e Ásia!

Seu livro está uma delícia, de uma doçura igual à das minhas lembranças daquele tempo. Reli encantado pelo seu ritmo tão original, — tão embalador na recurrência (sic) das palavras — "Chôro"4. Gostei muito dos versos para os 50 anos do Régio. Senti-me profundamente comovido pelos “Dados biográficos”. (...) (BPMP: SER99 (17)).

4 Trata-se do poema "Choro para Manuel Bandeira" escrito por Serpa: "Vate Bandeira, Manu Bandeira,/ é dura a vida. Que dura, a vida!/ Não há maneira. De que maneira/ ir à viagem tão requerida?// A vida avança. Como ela avança/nesta paragem,/ Uma esperança: só a esperança/ para a mais certa/ longa viagem.// $\mathrm{Ai}$, há tanto ano! Ai, há quanto ano/ quero este abraço! Jamais te abraço/ Mais desengano. Que desengano/ me deixa a vida sem esse passo!// Tanto queria... Como queria/ ver nestes sonhos realidade:/ saber contigo como é Poesia,/ Saber contigo como é Bondade!" (SERPA, 1954a: 98-99).

5 Poema da autoria de Serpa dedicado ao Dr. Eduardo dos Santos Silva, em que aquele não só diz, entre outras coisas, que foi sua "mocidade perdida nas mais loucas aspirações: boêmia, amor, ruído (...) troquei estudos e saber da Lei / pelos sonhos do grupo da presença”, como declara "A Liberdade pôs-me na prisão. (...) De quantos sofrem, sinto-me um irmão, / e tenho irmãos forçados que renego". (SERPA, in CARLOS, 1998: 234). Bandeira talvez se tenha comovido pela semelhança de experiências falhadas, que ele próprio refere em "Testamento". 
Mas Bandeira não parou aí. Respondeu ao "Choro" com o "Correio do Almanaque", que Serpa viria a publicar, em 1954, no Novo almanaque de lembranças luso-brasileiro. Datados de novembro de 1952, os versos do recifense diziam assim:

\author{
Saber comigo como é a Poesia?... \\ Saber comigo como é a Bondade?... \\ Pois quem mais sabe como é Poesia, \\ pois quem mais sabe como é Bondade \\ do que tu mesmo, bom e grande Alberto \\ de Serpa, amigo de peito aberto, \\ para os amigos de longe ou perto, \\ querido Alberto, fraterno Alberto? (BANDEIRA, in \\ SERPA, 1954b: 11).
}

\title{
O caso de Carlos Drummond de Andrade
}

Em 1940, em Lisboa é Longe, Serpa dedicou a Drummond um poema - "História", embora o texto estabeleça um diálogo com o poema "Debussy" de Bandeira. E, no já citado As Melhores Poesias Brasileiras (1944), o portuense incluiu três poemas de Drummond: "Sweet Home"; "Os mortos de sobrecasaca"; "Os ombros suportam o mundo". Isso revela um contato, pelo menos de Serpa, com a poesia de C.D.A.. E este deve ter tomado conhecimento da inclusão de seus poemas entre os melhores do Brasil bem como da dedicatória. Apesar de não ser do temperamento e dos hábitos de Carlos deixar de agradecer, a troca de correspondência entre Alberto de Serpa e Drummond não foi, ao que parece, muito grande. Talvez porque não os ligasse a figura de Antônio Nobre, como aconteceu com Ribeiro Couto e Manuel Bandeira, talvez porque Drummond representasse

6 Este poema foi depois incluído em Mafuá do Malungo com o título "Resposta a Alberto de Serpa" (cf. Bandeira, 1958: v.I, p. 546). 
uma outra vertente do Modernismo brasileiro que Serpa certamente admirava, mas com a qual não tinha afinidade. $\mathrm{Na}$ Biblioteca $\mathrm{Mu}-$ nicipal do Porto, há somente quatro cartas de Carlos para Alberto; e, no Arquivo-Museu de Literatura Brasileira da Fundação Casa de Rui Barbosa, apenas uma de Alberto para Carlos.

A primeira carta de Drummond para Alberto de Serpa data do Rio de Janeiro, 23 de junho de 1939 (BPMP M-SER-345(1)) O mineiro agradece ao portuense o livro A Vida é o Dia de Hoje, recém-publicado. A segunda, escrita também no Rio, data de dez anos depois - 31 de julho de 1949 - e é também de agradecimento agora pelo envio de outra publicação recente, Retrato e Lição de Gomes Leal, um conjunto de dois poemas, que saíra em 1948, pela Portugália ((BPMP M-SER-345(2)).

A terceira tem data de 19 de setembro de 1952 e agradece Pregão, poema escrito para o I Congresso de Poesia, em Segóvia (BPMP M-SER-345(3)).

A quarta foi escrita em 11 de junho de 1954 e é talvez a mais importante (BPMP M-SER-345(4)). A essa Drummond anexou a crítica que escreveu para o Correio da Manhã, de 10 de junho desse ano, sobre o Novo Almanaque de Lembranças Luso-Brasileiro, anexo esse também enviado por Bandeira com a carta de 13 de junho de 1954, que, aliás, Ribeiro Couto igualmente refere em correspondência dirigida a Serpa. Dizia assim o artigo de Carlos Drummond, que teve por título Imagens de Longe:

Este Almanach de Lembranças, que o correio acaba de trazer, foge ao comum dos Almanaques. (...) é um almanaque todo em versos, e seu autor, um grande poeta do Porto, Alberto de Serpa.

A primeira noção que se colhe de sua leitura é a existência de um laço, não político, não diplomático, não "dirigido", entre escritores portugueses e brasileiros, os quais se comunicam intensamente, à margem dos organismos de intercâmbio. Talvez em ne- 
nhum período essa comunicação haja sido tão viva como no atual, embora na aparência se observe pequeno interesse de um meio intelectual pelo outro. A ligação entre intelectuais brasileiros e seus confrades lusitanos, porém, faz-se numa base de fraternidade, alimentada pelos encontros pessoais que se vão tornando mais frequentes, e pela correspondência, que permitiu a homens como Mário de Andrade, e Jorge de Lima, sem jamais saírem do Brasil, participar dos “cavacos” de Lisboa, tão de perto como Ribeiro Couto, que lá viveu alguns anos. E se esse entendimento coloquial não é ainda mais perfeito, há de ser culpa do lado americano, que sabidamente tem certa alergia por escrever cartas, e nem sempre se dá ao trabalho de respondê-las a não ser em pensamento.

São muitos os amigos brasileiros do poeta (Alberto de Serpa), que ele celebra em graciosas composições, e se deixam de ser nomeados aqui é para não causar inveja aos que não figuram no grupo. Dos portugueses, há instantâneos inesquecíveis. Vemos, numa casinha da Beira, entre laranjais, Miguel Torga oferecer o seu bom vinho "que levanta as almas de toda queda". (...) Em frente ao cemitério de Portalegre, um casarão esconde o solitário José Régio, que aí vive entre antigualhas e que satisfaz seu desejo de viagens indo até ao liceu. Evoca-se um dia remoto, em que na companhia de Antônio Botto, Serpa foi em romagem ao Martinho da Arcada, para ver Fernando Pessoa. (...)

Versos de circunstância, os de Alberto de Serpa? Nem por isso são de qualidade menor. Toda circunstância se eleva transfigurada pelo raio poético. E em circunstância vivemos ${ }^{7}$. (...)

7 Em Passeios na Ilha, Drummond trata também de versos de circunstância com relação a Mafuá do Malungo, saído da oficina de João Cabral de Mello Neto, que Bandeira subintitulou "versos de circunstância": "Mas que é circunstância neste particular de versos? Se se incorpora à poesia, deixa de ser circunstância. Arte de transfigurar as circunstâncias, poderíamos rotular a poesia. A circunstância é sempre poetizável, e isso nos foi mostrado até o cansaço pelos grandes poetas de todos os tempos, sempre que um preconceito discriminatório não lhes travou o surto lírico”. E cita Verlaine, Mallarmé, Baudelaire. (ANDRADE, 1975: 90). 
Do homem Serpa, o seu melhor elogio é a recusa a prêmios e honras que alguém lhe quis dar e que ofenderiam a sua orgulhosa humildade: "Quero a solidão / e quero o poder / de poder dizer / quando queira, não”.

Mas a sua poesia sabe dizer sim com ternura, à vida e aos amigos. C.D.A. (ANDRADE, 1954b: 4).

Não há, entre os dois poetas, mesmo nessas poucas cartas, como se pode observar, confidências ou pedidos de livros e de outros favores, como ocorre na correspondência entre Alberto e Bandeira, ou entre Alberto e Couto (que não será aqui considerada, por limites de espaço, embora seja longa e bastante significativa, além de também Ribeiro Couto figurar nos dois Almanaques).

Talvez houvesse outras cartas de Serpa para Carlos Drummond, uma vez que, no Arquivo Museu de Literatura Brasileira da Fundação Casa de Rui Barbosa, o único exemplar da correspondência existente entre esses dois homens de Letras registra um agradecimento do português pelos elogios ao Novo Almanaque de Lembranças, enviados pelo brasileiro. Data de 20 de junho de 1954.

Claro que Carlos Drummond de Andrade já teria visto os dois almanaques, saídos, ambos em 1954, embora - lembramos - o primeiro, onde há um poema a ele dirigido, tivesse sido preparado em 52. E Serpa não os teria enviado sem, pelo menos, um cartão.

Além disso, o Almanaque organizado em 52 mostra a existência de alguma comunicação escrita anterior, pois nele, "Enquanto espero o livro Claro Enigma", poema de Serpa, diz assim:

Carlos Drummond de Andrade, grande poeta amigo. a nova novidade ainda não está comigo. 
Perdeu-se nos ares,

num voo leve, brando,

ou anda pelos mares

as sereias mais belas cativando?

Ou só esqueceria

o poeta o distante, de tanta pouca Poesia

que é como se não viva ou jamais cante?

Em vão convoquei aves

e convoquei sereias,

lembrando as penas graves

para quem retiver coisas alheias.

Agora, já só tento,

com versos que aí vão,

ser lembrado. - sedento,

faminto de Poesia e de Evasão. (SERPA, 1954a: 81-82).

Drummond deve ter recebido este primeiro Almanaque. Ou não teria enviado a resposta que figura no Novo Almanaque ("Reenviando o livro Claro Enigma"), e que vem reforçar a ideia de que houve mais troca de correspondência do que a existente:

Meu querido poeta,

o livro era bem pouco:

na garganta secreta,

algo de triste e rouco.

Perdeu-se acaso um dia, por entre Rio e Porto, como se perderia uma agulha, num horto. 


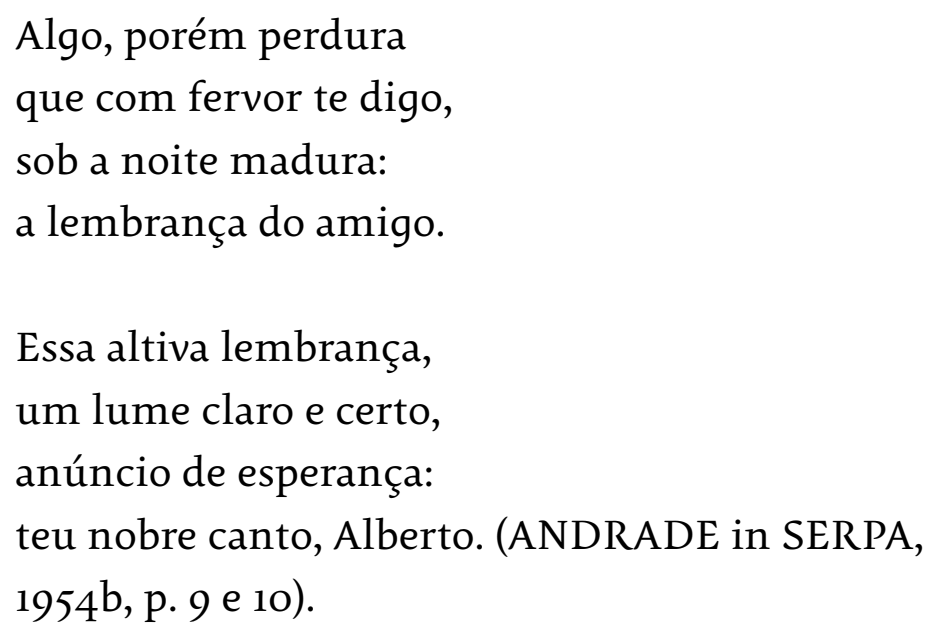

A parca existência de cartas e bilhetes é, pois, estranha, ainda mais que não só Drummond tinha o hábito de não deixar sem resposta quem lhe escrevia, como também preservou sempre o que lhe enviaram.

Embora Alberto interpele Carlos perguntando pelo Claro Enigma, o que se nota é uma certa reverência de um poeta para com o outro: Serpa envia seus livros (ou pelo menos um deles: Pregão, como se pode ver pela única carta existente no AMMLB/ FCRB dirigida a Drummond e datada de 20 de junho de 1954); Carlos chama "nobre canto" à poesia de Serpa e, em função do Novo Almanaque, escreve a crônica do Correio da Manhã acima transcrita, em que diz ser transfigurado pelo raio poético o circunstancial da poesia de Serpa, uma poesia que "sabe dizer sim com ternura, à vida e aos amigos" (ANDRADE, 1954, p. 4).

Assim, sem haver trocado uma correspondência farta com Alberto de Serpa, mas admirado por ele e representante do Modernismo brasileiro, mesmo sem ter em comum com o poeta português a admiração por Antônio Nobre, Carlos Drummond de Andrade figurou nas páginas dos almanaques criados pelo portuense. 


\section{Conclusão}

Guardando pelos almanaques um carinho especial, apesar de reconhecer neles "versos ingênuos", Alberto de Serpa, lembra os antigos, com seus registros de "inventos sensacionais, / heróis, politicos, altos vultos" e "longas viagens às mais ignotas/terras", "contos familiares", "passatempos", "anedotas", o "talhe doce" das "figurinhas", mas traça ele próprio "uns pobres versos para almanaque" (SERPA, 1954a, p. 4) e cria o seu Almanaque de Lembranças Luso-Brasileiro, diferente em tudo dos almanaques homônimos produzidos por Antônio Feliciano de Castilho e seus continuadores. Provocando e convocando para a resposta portugueses e brasileiros, obtém versos de Manuel Bandeira e Carlos Drummond, que, assim - e em função de gostos comuns, trocas de livros e de uma amizade sustentada por cartas - passam a ser não poetas de almanaque, mas poetas do Novo Almanaque de Lembranças Luso-Brasileiro, onde Alberto de Serpa os reúne a outros do Brasil, ficando deles "mais irmão, também, por Poesia" (SERPA, 1954b, p. 15).

RECEBIDO: 18/08/2021

Aprovado: $28 / 08 / 2021$

\section{REFERÊNCIAS}

Almanaque de lembranças luso-brasileiro para 1856. Lisboa: Tipografia Universal, 1855 .

Almanaque de lembranças luso-brasileiro para 1860 (bissexto). Lisboa: Tipografia Franco-Portuguesa, 1859.

ANDRADE, Carlos Drummond. "Imagens de Longe". Correio da manhã, ed. 18774, Rio de Janeiro, 10 de junho de $1954,1^{\circ}$ caderno, p.4.

ANDRADE, Carlos Drummond. 'Manuel Bandeira'. Passeios na ilha. Rio de Janeiro: Livraria José Olympio Editora, 1975, p. 83-92.

ANDRADE, Carlos Drummond. "Reenviando o livro Claro Enigma”. Novo almanaque de lembranças luso-brasileiro. (Porto) Imprensa Portuguesa, 1954b, p. 9-10. 
AMLB (ARQUIVO-MUSEU DE LITERATURA BASILEIRA). MB 117cp; CDA1603cp.

BPMP (BIBLIOTECA PÚBLICA MUNICIPAL DO PORTO): M-SER-99(2), M-SER-99(3), M-SER-99(4), M-SER 99(5), M-SER-99(8), M-SER-99(9), M-SER-99(11), M- SER-99(12) o1 e o2, M-SER-99(13) o1, M-SER-99-9(14), M-SER-99(15),M-SER-99(16),M-SER-99(17),M-SER-345(3),M-SER-345(2), M-SER-345(3), M-SER-345(4).

BANDEIRA, Manuel. "Correio do Almanaque". Novo almanaque de lembranças luso-brasileiro. (Porto) Imprensa Portuguesa, 1954b, p. 11.

BANDEIRA, Manuel. "Mafuá do Malungo". Poesia e prosa completas. Rio de Janeiro: Editora Aguilar, 1958, v.1, p. 447-504.

CARLOS, Luís Adriano. A poesia de Alberto de Serpa. Porto: Campo das Letras: 1998.

DUTRA, Eliana de Freitas. "Laços fraternos. A construção imaginária de uma comunidade cultural luso-brasileira no Almanaque de Lembranças". Revista do Arquivo Público Mineiro, Belo Horizonte, 2005, v. 1, p. 116-127.

FUNDAÇÃO CASA DE RUI BARBOSA. CENTRO DE LITERATURA BRASILEIRA. Inventário do arquivo Manuel Bandeira. Rio de Janeiro, 1989.

FUNDAÇÃO CASA DE RUI BARBOSA. ARQUIVO-MUSEU DE LITERATURA BRASILEIRA. Inventário do arquivo Carlos Drummond de Andrade. $2^{\mathrm{a}}$ ed. aum., Rio de Janeiro: Edições Casa de Rui Barbosa, 2002.

SERPA, Alberto de. As melhores poesias brasileiras. Lisboa: Portugália: 1944 .

SERPA, Alberto de. Almanaque de lembranças luso-brasileiro. Lisboa, Inquérito,1954a.

SERPA, Alberto de. Descrição. s.l.: Edições Presença, 1935.

SERPA, Alberto de. Evohe. Coimbra: s.n.,1924.

SERPA, Alberto de. Novo almanaque de lembranças luso-brasileiro. (Porto) Imprensa Portuguesa, 1954b.

SERPA, Alberto de. Pregão. Para o I congresso de poesia em Segóvia. s.l.: Saber, 1952. 


\section{MinicuRRículo}

Maria Aparecida Ribeiro é professora aposentada da Universidade de Coimbra, onde dirigiu o Instituto de Estudos Brasileiros da Faculdade de Letras. É membro integrado do Centro de Literatura Portuguesa, membro colaborador do CIEC e do CLEPUL. Entre suas obras, destacam-se: Teatro Brasileiro. Textos de Fundação. Glória e Infortúnio ou A Morte de Camões. António José ou O Poeta e a Inquisição. O Juiz de Paz da Roça (2002); A Carta de Caminha e seus Ecos (2003); Drummon(d)tezuma - correspondência entre Carlos Drummond de Andrade e Joaquim Montezuma de Carvalho (2004); Camões, personagem dramática. Dinamarca. (2014); Amélia Janny (1842-1914) (2019). 